Published in final edited form as:

Gastrointest Endosc. 2014 February ; 79(2): 289-296. doi:10.1016/j.gie.2013.08.006.

\title{
Endoscopic papillectomy: risk factors for incomplete resection and recurrence during long-term follow-up
}

\author{
Wiriyaporn Ridtitid, MD ${ }^{1,2}$, Damien Tan, MD ${ }^{1}$, Suzette E. Schmidt, BSN ${ }^{1}$, Evan L. Fogel, \\ MD1 , Lee McHenry, MD1, James L. Watkins, MD¹, Glen A. Lehman, MD¹, Stuart Sherman, \\ MD' ${ }^{1}$, and Gregory A. Coté, MD, MS ${ }^{1}$ \\ Indianapolis, Indiana, USA
}

\begin{abstract}
Background-Endoscopic papillectomy is increasingly used as an alternative to surgery for ampullary adenomas and other noninvasive ampullary lesions.
\end{abstract}

Objective-To measure short-term safety and efficacy of endoscopic papillectomy, define patient and lesion characteristics associated with incomplete endoscopic resection, and measure adenoma recurrence rates during long-term follow-up.

Design-Retrospective cohort study.

Setting-Tertiary-care academic medical center.

Patients-All patients who underwent endoscopic papillectomy for ampullary lesions between July 1995 and June 2012.

Intervention-Endoscopic papillectomy.

Main Outcome Measurements-Patient and lesion characteristics associated with incomplete endoscopic resection and ampullary adenoma-free survival analysis.

Results-We identified 182 patients who underwent endoscopic papillectomy, 134 (73.6\%) having complete resection. Short-term adverse events occurred in 34 (18.7\%). Risk factors for incomplete resection were jaundice at presentation (odds ratio [OR] $0.21,95 \%$ confidence interval [CI] 0.07-0.69; $P=.009$ ), occult adenocarcinoma (OR 0.06, 95\% CI, $0.01-0.36 ; P=.002$ ), and intraductal involvement (OR $0.29,95 \% \mathrm{CI}, 0.11-0.75 ; P=.011$ ). The en bloc resection technique was strongly associated with a higher rate of complete resection (OR 4.05, 95\% CI, 1.71-9.59; $P$ $=.001)$. Among patients with ampullary adenoma who had complete resection $(\mathrm{n}=107), 16$ patients (15\%) developed recurrence up to 65 months after resection.

Limitations-Retrospective analysis.

Copyright (@) 2013 by the American Society for Gastrointestinal Endoscopy

Reprint requests: Gregory A. Coté, MD, MS, Assistant Professor of Medicine, Indiana University School of Medicine, 550 North University Boulevard, UH 1634, Indianapolis, IN 46202.

${ }^{1}$ Indiana University School of Medicine, Indianapolis, Indiana, USA

${ }^{2}$ Chulalongkorn University, King Chulalongkorn Memorial Hospital, Thai Red Cross Society, Bangkok, Thailand

If you would like to chat with an author of this article, you may contact Dr Coté at gcote@iu.edu.

DISCLOSURE: No other financial relationships relevant to this publication were disclosed.

Presented at Digestive Disease Week, May 18-21, 2013, Orlando, Florida, USA. 
Conclusion-Jaundice at presentation, occult adenocarcinoma in the resected specimen, and intraductal involvement are associated with a lower rate of complete resection, whereas en bloc papillectomy increases the odds of complete endoscopic resection. Despite complete resection, recurrence was observed up to 5 years after papillectomy, confirming the need for long-term surveillance.

Endoscopic papillectomy is increasingly used as the first-line approach to resection for ampullary adenomas, having significantly lower morbidity compared with surgery in limited cohort studies. ${ }^{1}$ There are important knowledge gaps related to endoscopic papillectomy: (1) patient and lesion characteristics that are associated with the ability to achieve complete resection via endoscopy are unclear; (2) recurrence rates after complete endoscopic resection are incompletely reported ${ }^{2-5}$; (3) after tumor removal, optimal duration of endoscopic surveillance is unknown. The majority of ampullary lesions amenable to endoscopic resection are ampullary adenomas, which may originate sporadically or in the setting of familial adenomatous polyposis (FAP). Adenomas are considered precancerous lesions, having a risk of transformation to adenocarcinoma in $25 \%$ to $85 \%$ for sporadic cases and $4 \%$ for patients with FAP. ${ }^{6}$ Because of their malignant potential, resection of sporadic ampullary adenomas is recommended. However, it remains controversial as to which FAP-associated ampullary adenomas should be removed and which should be kept under surveillance. In patients with FAP, the potential risk of adenocarcinoma (ampullary or duodenal) is measured by the adenoma burden in the duodenum, typically quantified by using the Spigelman classification (stage 0-IV; depending on polyp number, size, histology, and severity of dysplasia). ${ }^{7}$

Surgical approaches for ampullary lesions include pancreaticoduodenectomy (ie, Whipple procedure) and transduodenal excision (eg, surgical ampullectomy). ${ }^{6}$ However, there is substantial morbidity $(25 \%-65 \%)$ and mortality $(0 \%-2 \%)$ associated with pancreaticoduodenectomy and transduodenal excision $(14 \%-33 \%, 0 \%-9 \%) \cdot{ }^{8-10}$ Although local surgical excision has lower morbidity compared with the Whipple procedure, limited data suggest that there is a higher $(30 \%)$ risk of recurrence. ${ }^{10}$ Previous studies suggest that endoscopic resection (endoscopic papillectomy) has comparable efficacy with lower morbidity ( $18 \%$ vs $42 \%$ for surgical ampullectomy) in properly selected patients. ${ }^{1}$ Limiting factors for endoscopic resection as a curative intervention are incomplete removal and recurrence. Although previous studies demonstrated the feasibility of endoscopic papillectomy for ampullary adenomas, these were limited by a small number of patients, short follow-up duration, and limited analysis of risk factors associated with long-term outcomes. ${ }^{2-4,11,12}$ We sought to analyze the short-term and long-term efficacy of endoscopic papillectomy for the treatment of ampullary lesions, with a particular emphasis on risk factors associated with incomplete resection and recurrence rates during follow-up. Although there are subtle histopathologic differences between a lesion arising from the duodenal aspect of the major papilla and arising from within the ampulla, we used the terms ampullectomy and papillectomy interchangeably in this article. 


\section{METHODS}

\section{Study population}

We conducted a retrospective cohort study of all patients who underwent attempted endoscopic papillectomy for known or suspected ampullary adenomas between July 1995 and June 2012. We excluded patients with lesions deemed unresectable at the time of EUS or ERCP because of extensive intraductal involvement $(>1 \mathrm{~cm})$, invasion of the duodenal submucosa, or lymph node invasion. We did not attempt endoscopic papillectomy in patients who had undergone a previous biopsy that confirmed adenocarcinoma. Patients were identified by using a database containing prospectively entered data that has been IRBapproved since 1994. We abstracted procedure reports and medical records for additional variables of interest. The study protocol was approved by our local institutional review board.

\section{Endoscopic technique}

Endoscopic papillectomy was performed by 1 of 6 endoscopists, each of whom performs more than 300 ERCPs per year. At the time of endoscopic resection, ERCP was routinely completed to (1) assess for intraductal extension and (2) identify the pancreatic orifice for placement of a prophylactic pancreatic duct stent. The decision to perform EUS before or at the time of ERCP was at the discretion of the treating endoscopist. ERCP and papillectomy were performed by using a side-viewing duodenoscope with a therapeutic $(4.2 \mathrm{~mm})$ working channel (Olympus Optical Co, Tokyo, Japan). In some cases, the endoscopist injected dilute epinephrine $(1: 10,000)$ into the submucosa to lift the lesion before resection. A needle-knife was used selectively to cauterize the tumor margin in an effort to create a groove for holding the snare in place. When possible, the entire papilla with tumor was grasped en bloc and resected by using standard electrocautery (Endostat HF electrosurgical generator; Microvasive, before November 1996 and ERBO-TOM 200 HF; ERBE USA, Marietta, Ga, thereafter). The power setting was $150 \mathrm{~W}$, with a coagulation effect of 2 or 3 on the cutting edges (ERBE USA). If a piecemeal approach was used, all abnormal-appearing tissue was resected by using a combination of snare and forceps electrocautery. If residual tissue was suspected after resection, the endoscopist attempted to ablate it by using the tip of a polypectomy multipolar probe or argon plasma coagulation. Biliary and pancreatic sphincterotomies along with placement of a pancreatic duct stent $(3 \mathrm{~F}, 4 \mathrm{~F}$, or $5 \mathrm{~F}$ pancreatic stent) were performed at the discretion of the treating endoscopist.

\section{Follow-up}

After the procedure, patients were discharged home unless there was a suspicion of postprocedure adverse event or high-risk comorbidity (eg, obstructive sleep apnea, congestive heart failure). The decision to perform a second endoscopy for retreatment or surveillance of the resection site was left to the treating endoscopist. Generally, if the endoscopist believed the lesion had been completely resected, a surveillance endoscopy was performed 6 to 12 months later. The patient underwent a repeat endoscopy sooner or was referred to surgery if complete resection was questionable, adenocarcinoma was identified on histopathologic review of the resection specimen, or stent removal was necessary. 


\section{Definitions}

Medical records were abstracted for relevant patient and lesion characteristics, including a history of FAP and reason for clinical presentation that included incidental findings during upper endoscopy, screening (FAP patients), abnormal laboratory test results, and overt symptoms such as recent acute pancreatitis or jaundice. Ampullary adenoma refers to an adenoma arising from the ampulla and/or papilla. Papillectomy refers to papillary resection, which may or may not involve ampullary resection. Relevant lesion characteristics included an estimate of size by endoscopic views, histopathologic size, and the presence of intraductal extension by ERCP and EUS. Final histopathology included adenoma, advanced adenoma (defined as tubulovillous adenoma, villous adenoma, or adenoma with high-grade dysplasia), adenocarcinoma, and all others. We categorized the case as being a complete resection when a patient who underwent a surveillance endoscopy had no endoscopic evidence of persistently abnormal tissue, with or without surveillance biopsies, at any time after the index procedure. Complete resection was further subcategorized into those who achieved complete resection after the first endoscopy and those who required 2 or more endoscopies.

We measured short-term ( $<30$ days after procedure) and long-term adverse event rates. Short-term adverse events including post-ERCP pancreatitis (PEP), hemorrhage, and perforation were defined based on consensus criteria. ${ }^{13}$ PEP was defined as new or worsening abdominal pain associated with new or prolonged hospitalization (at least 2 days) and elevation of serum amylase levels $>3$ times the upper limit of normal measured more than 24 hours after the procedure. ${ }^{14}$ ERCP-associated bleeding was defined as immediate bleeding during the procedure (requiring endoscopic intervention) or any time within 14 days of the procedure; the latter was defined as $\geq 2 \mathrm{~g} / \mathrm{dL}$ drop in hemoglobin level with associated clinical evidence of GI hemorrhage. Perforation was described as guidewireinduced perforation, periampullary perforation during sphincterotomy, or luminal perforation anywhere else. A long-term adverse event was defined as any procedure-related adverse event that occurred after 30 days, including biliary and/or pancreatic orifice stenosis. We categorized the case as being a recurrence when a patient had recurrence of adenoma and/or adenocarcinoma; the analysis of recurrence was limited to the subgroup of patients who met our definition of complete resection.

\section{Statistical analysis}

To identify patient, lesion, and technical characteristics that were associated with achieving complete resection, we dichotomized the study population into those with and without complete resection at any time. We described dichotomous variables by using simple proportions with $95 \%$ confidence intervals (CI) and compared groups by using the Fisher exact test (for variables having $<10$ events) or chi-square test. We described continuous variables by using mean and standard deviation and compared groups by using a standard $t$ test. Factors identified on univariate analysis as potentially associated with having a complete resection, defined as a $P$ value $<.10$, were included in a forward stepwise conditional regression model, with $\leq 4$ variables included at any time to avoid overfitting. In patients who achieved complete resection with at least 1 follow-up endoscopy, we described 
recurrence rates as a time-to-event outcome by using the Kaplan-Meier method. Statistical analyses were performed by using Stata version 11.2 (StataCorp LP, College Station, Tex).

\section{RESULTS}

Short-term outcomes During the 17-year study period, we identified 223 patients referred for endoscopic papillectomy; 41 patients were excluded for lesions that did not involve the major papilla. Of the remaining 182 patients, all underwent endoscopic papillectomy for suspected and/or known ampullary adenoma. Incidentally, 31 patients (17\%) were found to have a non-adenomatous lesion based on histopathologic analysis of the resected specimen (Fig. 1). These included inflammation and/or hyperplasia $(n=11)$, normal mucosa $(n=7)$, reactive atypia inconsistent with adenoma $(n=6)$, hamartoma $(n=3)$, carcinoid tumor $(n=$ 2), paraganglioma $(n=1)$, and gastric heterotopia $(n=1)$. In most of these cases, forceps biopsies of the papilla obtained at referring facilities suggested adenoma, prompting endoscopic papillectomy. In patients with adenomatous lesions confirmed by histopathology after papillectomy $(\mathrm{n}=151)$, findings included adenoma without advanced features $(\mathrm{n}=89)$, advanced adenoma $(n=50)$, and adenocarcinoma $(n=12)$.

Short-term ( $<30$ days) adverse events developed in 34 of 182 patients (18.7\%), including hemorrhage $(n=23,12.6 \%)$, perforation $(n=3,1.6 \%)$, pancreatitis $(n=7,3.8 \%)$, and myocardial infarction $(\mathrm{n}=1,0.5 \%)$. Of those with hemorrhage, 1 had severe bleeding and required surgical intervention. Of those with pancreatitis, 1 was moderate severity. Death occurred in 1 patient who developed acute myocardial infarction after the procedure. Of those having short-term adverse events, 9 patients required hospitalization (mean length of stay 6.7 days, range $1-17$ days) for mild pancreatitis $(n=2)$, moderate pancreatitis $(n=1)$, mild hemorrhage $(\mathrm{n}=1)$, severe hemorrhage $(\mathrm{n}=1)$, perforation $(\mathrm{n}=2)$, and myocardial infarction $(\mathrm{n}=1)$. Delayed adverse events occurred in 7 patients $(3.8 \%)$, including stenosis of the biliary $(n=2,1.1 \%)$, pancreatic $(n=2,1.1 \%)$, or both $(n=3,1.6 \%)$; all required extension sphincterotomy with or without orifice dilation. Of those having delayed adverse events, clinical presentations included acute pancreatitis $(\mathrm{n}=2)$ and abdominal pain with or without elevated liver and pancreas chemistry results $(n=5)$. Biliary and pancreatic sphincterotomies were performed at the time of initial papillectomy in 180 patients (98.9\%) and 157 patients (86.3\%), respectively. Pancreatic stent placement was performed in 156 patients $(85.7 \%)$. En bloc and piecemeal resection were performed in 89 patients (48.9\%) and 93 patients $(51.1 \%)$, respectively.

\section{Factors associated with complete resection}

Patient and lesion characteristics were compared between those with $(\mathrm{n}=134)$ and without $(\mathrm{n}=48)$ complete resection (Table 1). Patients with complete resection had a lower mean $( \pm$ standard deviation [SD]) age than those with incomplete resection (59.8 \pm 15.3 vs $65.8 \pm$ $17.1 ; P=.02)$. There was no significant difference in $\operatorname{sex}(P=.68)$ and clinical presentation $(P=.46)$ between groups. However, patients having jaundice at the time of presentation were more likely to have incomplete resection $(27.7 \%$ vs $4.5 \% ; P<.0001)$. There was no significant difference in tumor size by endoscopy $(P=.27)$ or histopathology $(P=.97)$ between groups, although size measurements at histology may have been inaccurate in the 
setting of piecemeal resection. Lesions removed en bloc were significantly smaller (17.4 \pm $9.4 \mathrm{~mm})$ than those removed in a piecemeal fashion $(23.6 \pm 13.3 \mathrm{~mm} ; P=.02)$. The probability of adenocarcinoma within the resected specimen was significantly higher among patients with incomplete resection $(20.8 \%$ vs $1.5 \% ; P<.001)$.

Endoscopic variables were compared between groups (Table 2). EUS was performed at similar frequencies in both populations, and there was no significant difference in intraductal involvement as observed during EUS examination (6.4\% with complete resection vs $13.3 \%$ with incomplete resection; $P=.39$ ). During ERCP, patients with incomplete resection had a significantly higher rate of intraductal extension $(31.3 \%$ vs $9.0 \% ; P=.0002)$. Eight patients $(11.3 \%)$ had evidence of intraductal invasion at ERCP, which was missed at EUS. Of patients having jaundice at the time of presentation $(n=19), 7$ patients $(36.8 \%)$ had intraductal involvement. There was no statistically significant difference in patients who underwent adjuvant cautery of the residual lesion $(29.1 \%$ vs $27.1 \% ; P=.79)$ and biliary sphincterotomy $(99.2 \%$ vs $100.0 \% ; P=.55)$, whereas patients with complete resection had a higher rate of pancreatic sphincterotomy $(91.7 \%$ vs $70.8 \% ; P=.003)$ and pancreatic stent placement $(91.0 \%$ vs $70.8 \% ; P=.006)$ than did those with incomplete resection. Patients who underwent papillectomy with the en bloc technique had a significantly higher probability of achieving complete resection than those who did not $(57.5 \%$ vs $22.9 \% ; P<$. 001). Patients who underwent papillectomy with piecemeal resection had a significantly larger mean $( \pm \mathrm{SD})$ size of tumors by pathology than those who had the en bloc technique $(20.2 \pm 14.3 \mathrm{~mm}$ vs $13.5 \pm 6.5 \mathrm{~mm} ; P<.001)$.

When the adenoma is considered as the base outcome, the odds of achieving a complete resection were similar for advanced adenomas and non-adenomatous lesions but were significantly lower in the setting of adenocarcinoma (odds ratio [OR] 0.07, 95\% CI, 0.010.34) (Table 3). After we adjusted for variables potentially associated with having a complete resection on univariate analysis, jaundice (OR 0.21, 95\% CI, 0.07-0.69; $P=.009$ ), adenocarcinoma (OR $0.06,95 \% \mathrm{CI}, 0.01-0.36 ; P=.002)$, and intraductal involvement $(<1$ $\mathrm{cm})$ during ERCP (OR $0.29,95 \% \mathrm{CI}, 0.11-0.75 ; P=.011)$ were significantly associated with a lower odds of achieving complete resection. The ability to perform an en bloc resection was significantly associated with greater odds of achieving complete resection (OR $4.05,95 \%$ CI, 1.71-9.59; $P=.001)$.

\section{Ampullary adenoma recurrence rates}

Among patients with ampullary adenomas $(\mathrm{n}=151)$ who achieved complete resection $(\mathrm{n}=$ 107), recurrence occurred in 16 patients (15\%) as early as 7 months and as late as 65 months after the primary lesion was removed (Fig. 2). Patients with sporadic and FAP adenomas had similar risks of recurrence during follow-up (mean 22.7 months, range 1-190 months).

\section{DISCUSSION}

Because of its lower morbidity, endoscopic papillectomy is an accepted alternative to surgical resection in properly selected patients with non-carcinomatous ampullary lesions. The major concerns with endoscopic papillectomy are acute adverse events, incomplete resection, and lesion recurrence. Previous smaller studies established the efficacy of 
endoscopic papillectomy in patients with ampullary adenomas..$^{2-4,11,12}$ In previous reports, complete resection rates ranged from $77 \%$ to $93 \%$. Fifty-five patients were reported in our previous study, which had complete resection of $67.3 \%$ and recurrence in about a third of patients. ${ }^{2}$ Risk factors associated with incomplete resection were not clarified in these studies. One study demonstrated that the complete resection rate was lower in patients with intraductal involvement of ampullary adenoma. ${ }^{4}$ The study compared endoscopic papillectomy for treatment of benign papillary lesions without and with intraductal growth $(\mathrm{n}=75 \mathrm{vs} \mathrm{n}=31) .{ }^{4}$ Complete resection was achieved in $83 \%$ without and $46 \%$ with intraductal growth $(P<.001)$. Another study (21 patients evaluated over a 12 -year period) demonstrated endoscopic failure in $74 \%$, defined as the inability to remove the lesion completely regardless of the number of sessions, recurrence treated surgically, or discovery of carcinoma beyond the mucosal layer. ${ }^{5}$ In recent small series, endoscopic balloon dilation facilitated complete adenoma resection in patients with intraductal extension with a short follow-up period. ${ }^{15-17}$

Consistent with previous studies, we report a rate of complete endoscopic resection of $74 \%$ in patients with ampullary adenoma. Jaundice at the time of presentation, intraductal involvement at ERCP, and the presence of adenocarcinoma in the resected specimen were associated with significantly higher odds of incomplete resection. In patients having 1 or more of these characteristics, the endoscopist should be highly vigilant for residual pathology. In these cases, an attempt at endoscopic resection may still be reasonable, particularly among patients who are poor operative candidates. In fact, 2 of 12 patients with adenocarcinoma underwent complete endoscopic resection; in other cases, papillectomy confirmed the histopathologic diagnosis, where previous biopsies had been falsely negative. Based on our observations, en bloc resection should be used when feasible; if piecemeal resection is required, earlier surveillance is strongly advised. The en bloc technique provides a clear margin to survey for residual adenomatous tissue. It is logical that jaundice would be associated with incomplete resection because there is a higher correlation with adenocarcinoma.

To date, there are no prospective, randomized, comparative effectiveness studies of endoscopic papillectomy and surgical ampullectomy. Similar to our observations, previous studies have suggested that endoscopic papillectomy is feasible among patients with noninvasive lesions. ${ }^{1,2,4,12}$ Our observed PEP rate (3.8\%) was low, with only 1 case of moderate severity, likely due to the frequent $(85.7 \%)$ use of pancreatic duct stents. ${ }^{18}$ The impact of biliary and pancreatic sphincterotomy at the time of papillectomy on long-term rates of stenosis requires further investigation. It is possible, particularly with pancreatic sphincterotomy, that recurring stenosis of the sphincter may be increased by the use of electrocautery. However, we observed a low rate (3.8\%) of recurring stenosis with the nearuniversal (98.9\%) use of biliary sphincterotomy and high use $(86.3 \%)$ of pancreatic sphincterotomy at the time of endoscopic resection. However, decades of follow-up are needed to define the true rate of recurring stenosis.

The optimal frequency and duration of endoscopic surveillance after endoscopic papillectomy are unknown. Based on our Kaplan-Meier analysis, risks of recurrence are similar for patients with and without FAP. Previous studies have reported adenoma 
recurrence rates of $10 \%$ to $33 \%$, but follow-up is highly variable. ${ }^{2-4,19}$ We observed recurrence in a small number of individuals even after 5 years, suggesting that long-term and potentially indefinite surveillance is reasonable, considering age and comorbidity. Study limitations include its retrospective design, variable endoscopic equipment and resection techniques, and limited endoscopic follow-up $>5$ years after the primary resection.

In conclusion, endoscopic papillectomy is a reasonable alternative to surgical resection for non-carcinomatous lesions of the papilla. Three negative prognostic factors including the presence of jaundice at the time of presentation, intraductal extension, and adenocarcinoma found in the resected specimen increase the likelihood of an incomplete resection. In patients with 1 or more of these characteristics, alternative resection strategies should be considered; if resection has been completed, close surveillance is warranted. When feasible, an en bloc approach is positively associated with complete endoscopic resection. In all patients with ampullary adenomas (FAP and sporadic), there is a small but measurable risk of recurrence up to 5 years after endoscopic resection. Therefore, longterm surveillance is warranted in appropriate individuals. Comparative effectiveness studies of endoscopic versus surgical resection are needed, as are larger populationbased studies to determine the optimal frequency and duration of after-resection surveillance.

\section{Acknowledgments}

The fellowship of W. Ridtitid was sponsored in part by an international gastrointestinal training grant from the American College of Gastroenterology.

\section{Abbreviations}

FAP familial adenomatous polyposis

PEP post-ERCP pancreatitis

\section{REFERENCES}

1. Ceppa EP, Burbridge RA, Rialon KL, et al. Endoscopic versus surgical ampullectomy: an algorithm to treat disease of the ampulla of vater. Ann Surg. 2013; 257:315-322. [PubMed: 23059497]

2. Cheng CL, Sherman S, Fogel EL, et al. Endoscopic snare papillectomy for tumors of the duodenal papillae. Gastrointest Endosc. 2004; 60:757-764. [PubMed: 15557951]

3. Norton ID, Gostout CJ, Baron TH, et al. Safety and outcome of endoscopic snare excision of the major duodenal papilla. Gastrointest Endosc. 2002; 56:239-243. [PubMed: 12145603]

4. Bohnacker S, Seitz U, Nguyen D, et al. Endoscopic resection of benign tumors of the duodenal papilla without and with intraductal growth. Gastrointest Endosc. 2005; 62:551-560. [PubMed: 16185970]

5. Boix J, Lorenzo-Zuniga V, Moreno de Vega V, et al. Endoscopic resection of ampullary tumors: 12year review of 21 cases. Surg Endosc. 2009; 23:45-49. [PubMed: 18398649]

6. El H II, Cote GA. Endoscopic diagnosis and management of ampullary lesions. Gastrointest Endosc Clin N Am. 2013; 23:95-109. [PubMed: 23168121]

7. Spigelman AD, Williams CB, Talbot IC, et al. Upper gastrointestinal cancer in patients with familial adenomatous polyposis. Lancet. 1989; 2:783-785. [PubMed: 2571019]

8. Winter JM, Cameron JL, Olino K, et al. Clinicopathologic analysis of ampullary neoplasms in 450 patients: implications for surgical strategy and long-term prognosis. J Gastrointest Surg. 2010; 14:379-387. [PubMed: 19911239] 
9. de Castro SM, van Heek NT, Kuhlmann KF, et al. Surgical management of neoplasms of the ampulla of Vater: local resection or pancreatoduodenectomy and prognostic factors for survival. Surgery. 2004; 136:994-1002. [PubMed: 15523392]

10. Martin JA, Haber GB. Ampullary adenoma: clinical manifestations, diagnosis, and treatment. Gastrointest Endosc Clin N Am. 2003; 13:649-669. [PubMed: 14986792]

11. Bohnacker S, Soehendra N, Maguchi H, et al. Endoscopic resection of benign tumors of the papilla of vater. Endoscopy. 2006; 38:521-525. [PubMed: 16767591]

12. Yamao $\mathrm{T}$, Isomoto $\mathrm{H}$, Kohno $\mathrm{S}$, et al. Endoscopic snare papillectomy with biliary and pancreatic stent placement for tumors of the major duodenal papilla. Surg Endosc. 2010; 24:119-124. [PubMed: 19517183]

13. Anderson MA, Fisher L, Jain R, et al. Complications of ERCP. Gastrointest Endosc. 2012; 75:467473. [PubMed: 22341094]

14. Cotton PB, Lehman G, Vennes J, et al. Endoscopic sphincterotomy complications and their management: an attempt at consensus. Gastrointest Endosc. 1991; 37:383-393. [PubMed: 2070995]

15. Dzeletovic I, Topazian MD, Baron TH. Endoscopic balloon dilation to facilitate treatment of intraductal extension of ampullary adenomas (with video). Gastrointest Endosc. 2012; 76:12661269. [PubMed: 23021163]

16. Meine GC, Baron TH. Endoscopic papillary large-balloon dilation combined with endoscopic biliary sphincterotomy for the removal of bile duct stones (with video). Gastrointest Endosc. 2011; 74:1119-1126. quiz 5 e1-5. [PubMed: 21944309]

17. Kim JH, Moon JH, Choi HJ, et al. Endoscopic snare papillectomy by using a balloon catheter for an unexposed ampullary adenoma with intraductal extension (with videos). Gastrointest Endosc. 2009; 69:1404-1406. [PubMed: 19152886]

18. Harewood GC, Pochron NL, Gostout CJ. Prospective, randomized, controlled trial of prophylactic pancreatic stent placement for endoscopic snare excision of the duodenal ampulla. Gastrointest Endosc. 2005; 62:367-370. [PubMed: 16111953]

19. Catalano MF, Linder JD, Chak A, et al. Endoscopic management of adenoma of the major duodenal papilla. Gastrointest Endosc. 2004; 59:225-232. [PubMed: 14745396] 


\section{Take-home Message}

- In patients having 1 or more of 3 negative prognostic factors, alternative resection strategies should be considered.

- When feasible, an en bloc approach is positively associated with complete endoscopic resection. In all patients with ampullary adenomas (familial adenomatous polyposis and sporadic), there is a small but measurable risk of recurrence up to 5 years after endoscopic resection. 


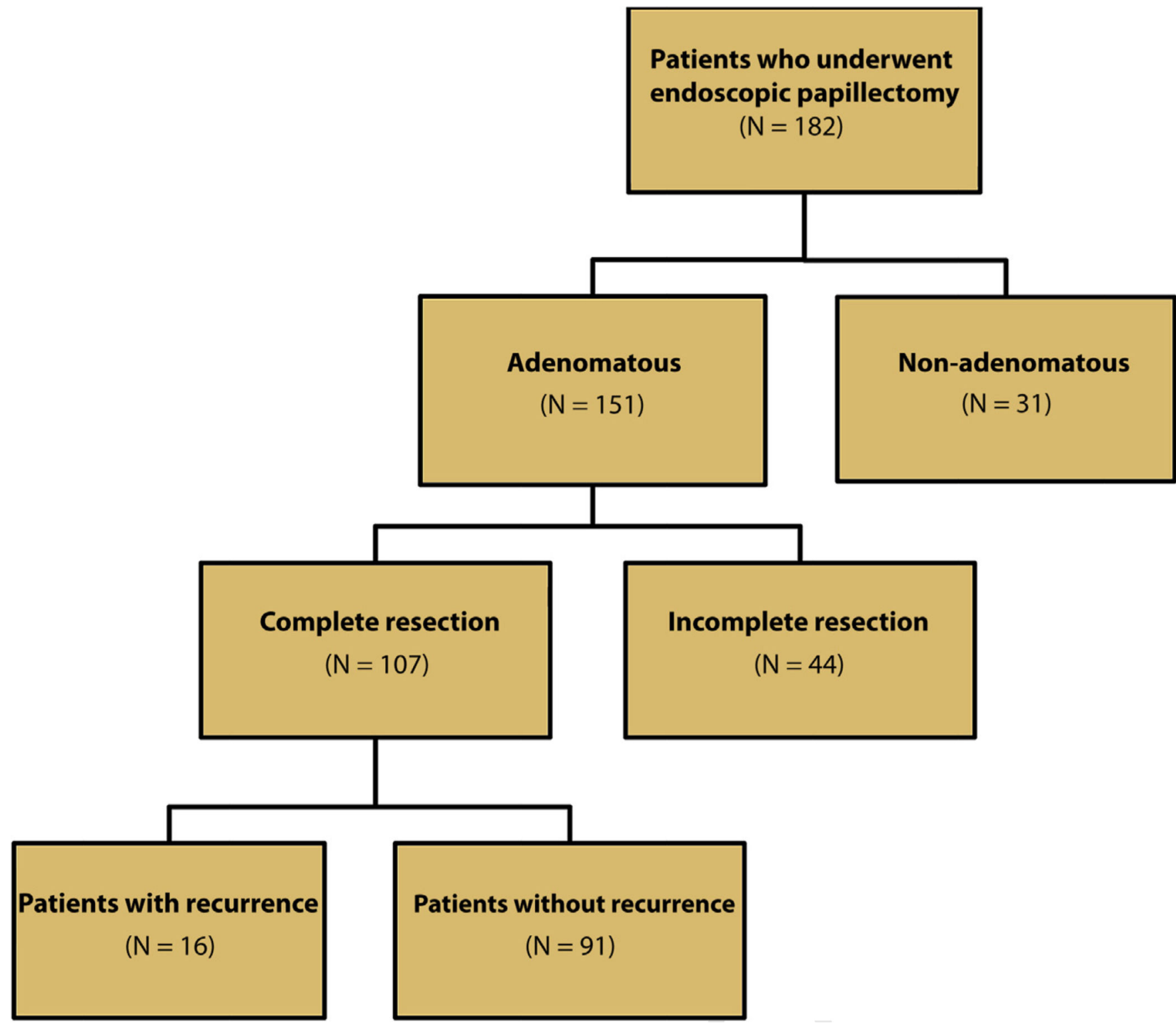

Figure 1.

Patient cohort: Endoscopic papillectomy between July 1995 and June 2012. 


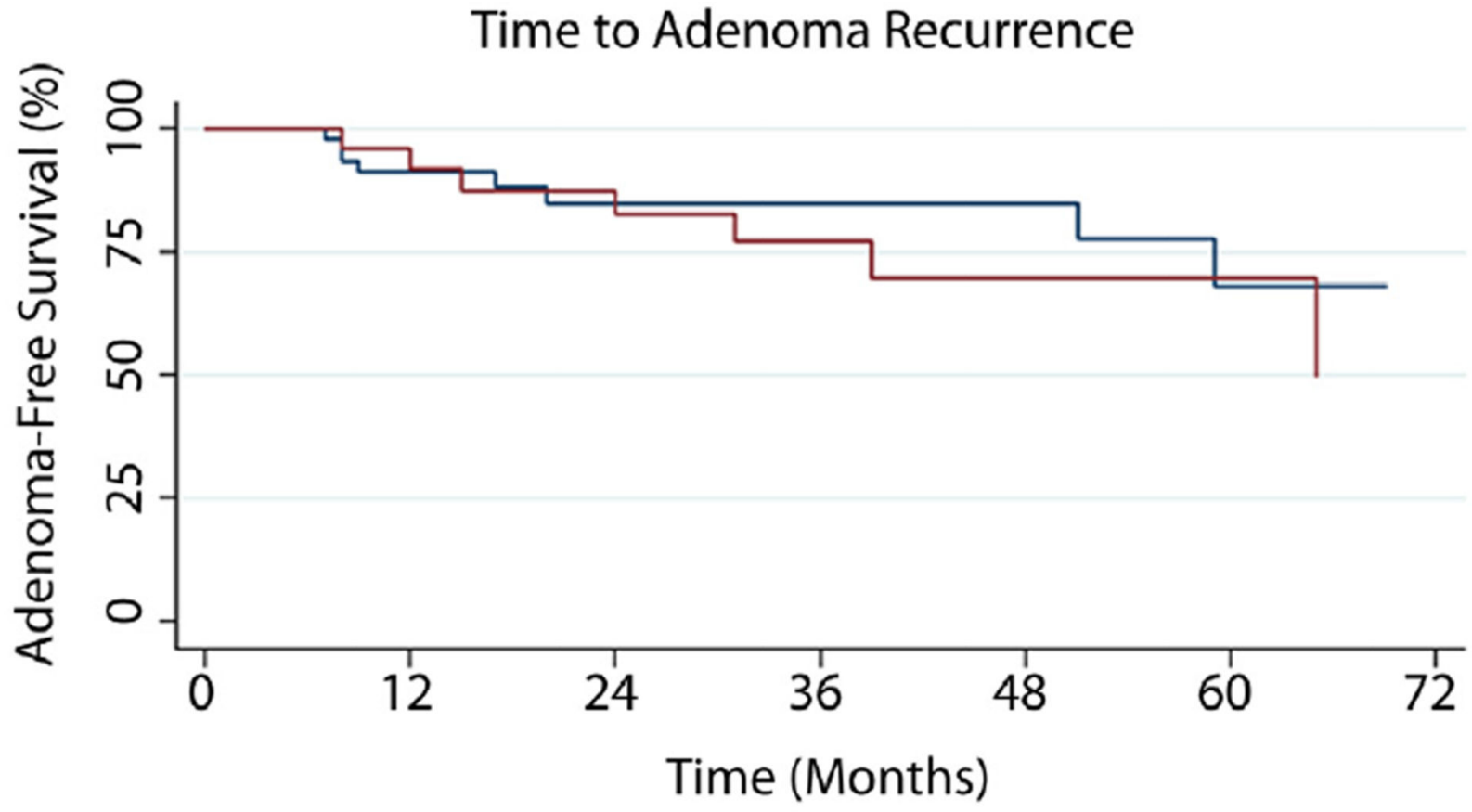

Number at risk

Sporadic 62

39

FAP 29

23

24

19

14

8

7
7

6

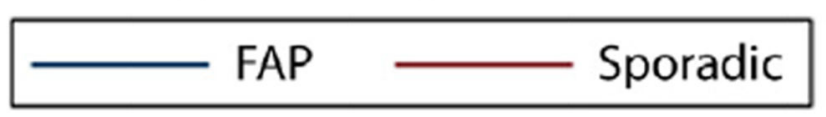

Figure 2.

Adenoma-free survival after endoscopic papillectomy. 
TABLE 1

Baseline characteristics of patients and ampullary lesions $(\mathrm{n}=182)$

\begin{tabular}{|lccc|}
\hline Variable & Complete resection $(\mathbf{n}=\mathbf{1 3 4})$ & Incomplete resection $(\mathbf{n}=\mathbf{4 8})$ & $\boldsymbol{P}$ value \\
\hline Age, mean $( \pm \mathrm{SD}), \mathrm{y}$ & $59.8 \pm 15.3$ & $65.8 \pm 17.1$ & .02 \\
\hline$\%$ Female, $(\%, 95 \% \mathrm{CI})$ & $50.7(42.3-59.2)$ & $54.2(40.1-68.3)$ & .68 \\
\hline$\%$ Jaundice, $(\%, 95 \% \mathrm{CI})$ & $4.5(1.0-8.0)$ & $27.7(14.9-40.4)$ & $<.0001$ \\
\hline Clinical presentation $(\%, 95 \% \mathrm{CI})$ & & & $.46^{*}$ \\
\hline Incidental finding & $32.8(24.8-40.9)$ & $22.9(10.8-35.0)$ & \\
\hline FAP screening & $28.4(20.6-36.1)$ & $25.0(12.5-37.5)$ & \\
\hline Abnormal laboratory test results ${ }^{\dagger}$ & $8.2(3.5-12.9)$ & $12.5(3.0-22.0)$ & \\
\hline Overt symptoms ${ }^{\dagger}$ & $26.9(19.3-34.4)$ & $37.5(23.6-51.4)$ & \\
\hline Others & $3.7(0.0-7.0)$ & $2.1(0.0-6.2)$ & \\
\hline Ampullary lesion & & & .27 \\
\hline Mean $( \pm$ SD) size by endoscopy $(\mathrm{mm})$ & $19.8 \pm 11.2$ & $23.4 \pm 14.4$ & .97 \\
\hline Mean $( \pm$ SD) size by pathology $(\mathrm{mm})$ & $16.6 \pm 11.6$ & $16.5 \pm 10.4$ & \\
\hline Histology $(\%, 95 \%$ CI $)$ & & $45.8(31.5-60.2)$ & \\
\hline Adenoma (without advanced features) & $48.9(42.2-57.5)$ & $25.0(12.5-37.5)$ & \\
\hline Advanced adenoma & $29.0(21.2-36.9)$ & $20.8(9.1-32.5)$ & \\
\hline Adenocarcinoma & $1.5(0.0-3.6)$ & $8.3(0.4-16.3)$ & \\
\hline Other & $20.6(13.6-27.6)$ & & \\
\hline
\end{tabular}

$S D$, Standard deviation; $C I$, confidence interval; $F A P$, familial adenomatous polyposis.

Fisher exact test

${ }^{\dagger}$ Elevated liver function test results or amylase or lipase levels.

${ }^{+}$Unexplained pancreatitis, abdominal pain, or jaundice. 
TABLE 2

Endoscopic findings and therapy $(\mathrm{n}=182)$

\begin{tabular}{|lccc|}
\hline Variable & Complete resection $(\mathbf{n}=\mathbf{1 3 4})$ & Incomplete resection $(\mathbf{n}=48)$ & $\boldsymbol{P}$ value \\
\hline EUS done before ERCP $(\%, 95 \% \mathrm{CI})$ & $40.3(32.0-48.6)$ & $35.4(21.9-48.9)$ & .55 \\
\hline Intraductal involvement $^{*}$ & $6.4(0.0-13.4)$ & $13.3(0.0-30.5)$ & .39 \\
\hline ERCP findings $(\%, 95 \% \mathrm{CI})$ & & & \\
\hline Intraductal involvement & $9.0(4.1-13.8)$ & $31.3(18.1-44.4)$ & .0002 \\
\hline Pancreas divisum & $6.9(2.6-11.3)$ & $10.5(0.8-20.3)$ & .46 \\
\hline Therapy $(\%, 95 \% \mathrm{CI})$ & & & \\
\hline En bloc resection & $57.5(49.1-65.8)$ & $22.9(11.0-34.8)$ & $<.0001$ \\
\hline Adjuvant cautery & $29.1(21.4-36.8)$ & $27.1(14.5-39.7)$ & .79 \\
\hline Biliary sphincterotomy & $99.2(97.2-100.0)$ & $100.0(100.0-100.0)$ & .55 \\
\hline Pancreatic sphincterotomy & $91.7(87.0-96.4)$ & $70.8(58.0-83.7)$ & .0003 \\
\hline Pancreatic stent placement & $91.0(86.1-95.8)$ & $70.8(58.0-83.7)$ & .0006 \\
\hline
\end{tabular}

CI, Confidence interval.

*

EUS intraductal involvement is the proportion of patients who underwent EUS before endoscopic papillectomy. 
TABLE 3

Relative risks of complete resection based on histology

\begin{tabular}{|lcc|}
\hline Histology & $\begin{array}{l}\text { Relative risk } \\
(\mathbf{\%}, \mathbf{9 5 \%} \mathbf{C I})\end{array}$ & $\boldsymbol{P}$ value \\
\hline Adenoma (without advanced features) & Base outcome & N/A \\
\hline Advanced adenoma & $1.09(0.48-2.45)$ & .84 \\
\hline Adenocarcinoma & $0.07(0.01-0.34)$ & .001 \\
\hline Other & $2.32(0.73-7.38)$ & .154 \\
\hline
\end{tabular}

CI, Confidence interval. 